\title{
UTILIZAÇÃO DO TARGET COSTING E DE OUTRAS TÉCNICAS DE CUSTEIO: UM ESTUDO EXPLORATÓRIO EM MUNICÍPIOS DE SANTA CATARINA
}

\author{
Koki Ono \\ Prof. Ms. da Universidade do Vale do Itajaí - SC \\ E-mail: onokoki@terra.com.br \\ Antonio Robles Junior \\ Prof. Dr. do Depto. de Contabilidade e Atuária da FEA/USP - SP \\ E-mail: aroblesjr@usp.br
}

\section{RESUMO}

Este artigo é resultado de estudo efetuado para formulação da Dissertação de Mestrado. Neste trabalho é abordado o referencial teórico sobre o Sistema de Gerenciamento de Custos, denominado "Target Costing", desenvolvido pelos japoneses nos anos sessenta, e que adotou a técnica americana chamada Engenharia de Valor, a qual consiste no cálculo do custo a partir do preço de venda estabelecido pelo mercado. Sua aplicação é especialmente importante num ambiente de competitividade empresarial. A pesquisa objetivou levantar dados e conhecer, através da pesquisa exploratória descritiva, quais métodos, sistemas ou técnicas de custeio são utilizados pelas empresas de médio e grande porte, localizadas em municípios do Estado de Santa Catarina, principalmente nas cidades de Itajaí, Navegantes, Ilhota, Gaspar, Blumenau, Brusque, Joinville e Tijucas, visando identificar propensões à utilização do Sistema de Gerenciamento de Custo "Target Costing". Adicionalmente, buscou-se levantar dados através da aplicação de questionários junto aos professores das disciplinas de custos, nos cursos de graduação em Ciências Contábeis e Administração das Instituições de Ensino Superior nos municípios de Itajaí, Blumenau, Brusque, Joinville e Florianópolis.

Palavras-chave: Target Costing; Métodos e Sistemas de Custeio.

\section{ABSTRACT}

This article is the result of a study carried out in preparation for a Masters Dissertation and addresses the theoretical framework of the Target Costing Management System, developed by the Japanese during the 1960s. It is based on an American technique known as Value Engineering, which calculates the cost of a product based on the sale price determined by the market. Its application is particularly important in a competitive business environment. This study aims to collect data and find out, through a descriptive and exploratory research, which costing methods, systems or techniques are used by large and medium-size companies located in Brazilian towns in the State of Santa Catarina, specifically in Itajaí, Navegantes, Ilhota, Gaspar, Blumenau, Brusque, Joinville and Tijucas, in order to identify trends in the use of the "Target Costing" Cost Management System. Data were also collected by means of a questionnaire, applied among cost management teachers in undergraduate Accountancy and Business Administration courses in Higher Education Institutions in Itajaí, Blumenau, Brusque, Joinville and Florianópolis.

Keywords: Target Costing; Costing Methods and Systems. 


\section{INTRODUÇÃO}

\subsection{Apresentação}

Este artigo é resultado do estudo efetuado para formulação da Dissertação de Mestrado pela Faculdade de Economia, Administração e Contabilidade da Universidade de São Paulo.

Neste trabalho são abordados:

- O referencial teórico sobre o Sistema de Gerenciamento de Custos "Target Costing";

- O resultado da investigação dos Métodos, Técnicas, Filosofias ou Sistemas de Custos utilizados pelas empresas industriais localizadas em municípios do estado de Santa Catarina, visando constatar a propensão para utilização do Target Costing;

- O nível de divulgação desta ferramenta de gestão de custos nos cursos de Ciências Contábeis e Administração das Instituições de Ensino Superior IES da região.

\subsection{Justificativa}

Nos últimos anos, o mundo vem passando por uma verdadeira revolução. Hoje, com a transformação de uma economia localizada em uma economia globalizada, as empresas precisam ser muito mais competitivas para sobreviverem, pressionadas pela concorrência muito maior entre empresas.

Devido a essa revolução no mundo dos negócios, as empresas necessitam trabalhar cada vez mais para oferecer produtos de qualidade, úteis e funcionais, a preços cada vez menores e, conseqüentemente, com uma margem de lucro cada vez mais reduzida. Assim, uma competente administração de custos dos produtos torna-se um fator fundamental para o sucesso da organização.

Com os avanços tecnológicos aliados aos meios de comunicação, os consumidores finais passaram a ser cada vez mais exigentes quanto a qualidade, utilidade e funcionalidade dos produtos. Com isto, as empresas foram pressionadas a firmar os seus preços de acordo com o mercado. Com essa mudança, as organizações precisaram se adequar a essa nova realidade, na qual o preço de venda é a base para se estabelecer os custos, adicionando remuneração mínima para a sobrevivência da organização.
Essa nova abordagem requerida na administração de custos contribuiu para o surgimento de vastas literaturas na busca de Métodos, Técnicas, Filosofias ou Sistemas de Custos, com objetivos de aumentar a produtividade, reduzir custos, otimizar os resultados, sem reduzir a qualidade, utilidade e funcionalidade dos produtos. Dentre estas literaturas, destacam-se os Métodos de Custeio: Pleno, como RKW (Reichskuratorium für Wirtschafilichtkeit); Direto, tendo a Margem de Contribuição como sua principal informação; e Custo-Padrão como controle. Surgiram também os Sistemas de Custos, sejam eles considerados como Métodos, Técnicas ou Filosofias de Gestão, como: JIT (Just-in-Time) no Japão, em meados de 1970; a TOC (Theory of Constraints), em Israel, no início da década de 70; Sistema Kaizen, no Japão, na década de 60; TQM (Total Quality Management), ABC (Activity Based Costing), nas primeiras décadas do século $X X$, sendo que a sua divulgação se deu a partir da segunda metade dos anos 80; ABM, na década de 90; UEP (Unidade de Esforço de Produção), trazido ao Brasil por Franz Allora, no início dos anos 60; GECON (Sistema de Gestão Econômica), que foi idealizado e está sendo desenvolvido por uma equipe de professores da USP coordenada pelo professor Armando Catelli, a partir da década de 70; Target Costing, ou Genka Kikaku em japonês, ou Custeio Alvo, sendo que o foco desse estudo, originalmente criado pelos japoneses, nos anos 60, foi baseado na idéia americana de Engenharia de Valor.

Com o presente trabalho, buscou-se investigar as empresas localizadas nos municípios de: Itajaí, Ilhota, Gaspar, Blumenau, Brusque e Joinville no estado de Santa Catarina, regiões estas consideradas pólo industrial no ramo têxtil, vestuário, confecções, alimentos, metal-mecânicos e revestimentos, visando constatar propensões à utilização do Target Costing. Procurou-se investigar ainda o nível de conhecimento deste instrumento de gestão de custos pelos professores da área de custos, nos cursos de Ciências Contábeis e Administração das IES.

\subsection{Métodos e Técnicas}

O presente estudo utilizou, na pesquisa, uma abordagem empírico-analítica de caráter quantitativo e qualitativo. A pesquisa ficou delimitada a trinta 
e cinco empresas industriais com mais de $500 \mathrm{em}$ pregados, localizadas nas cidades de Itajaí, Brusque, Blumenau, Ilhota, Gaspar, Joinville, Tijucas, e duas empresas localizadas nas cidades de Joaçaba e Videira, por serem consideradas importantes para o trabalho.

Para a pesquisa, foram utilizados dois instrumentos para coleta de dados. Um, entrevista direta com os gestores da área de custos - com vinte e duas perguntas, e outro, questionário (com onze perguntas), encaminhado via correio eletrônico, aos professores que lecionam as disciplinas da área de custos nos cursos de Ciências Contábeis e Administração das Instituições de Ensino Superior localizadas nas cidades de Blumenau, Brusque, Florianópolis, Itajaí e Joinville.

Para analisar e diagnosticar os dados coletados, seja por entrevista direta ou via correio eletrônico, utilizou-se um conjunto de técnicas chamado de análise de conteúdo e uma ferramenta estatística denominada Q-quadrado e Medida de Tendência Central, o percentil.

As entrevistas foram transcritas e encadernadas em volume com 285 páginas. Os questionários respondidos pelos professores também foram encadernados. Ambos volumes, encontram-se em poder do autor e por sigilo não fazem parte do material divulgado na dissertação de mestrado.

\section{PRESSUPOSTOS TEÓRICOS DO TARGET COSTING}

\section{Definição}

Nos primórdios da história, os humanos sobreviveram, principalmente, por sua capacidade associativa e sua inteligência. Conforme foram se passando os séculos, essa sobrevivência mudou, passando a depender de uma combinação de associação e desenvolvimento cerebral. Nessa realidade, surge a necessidade não só do desenvolvimento do cérebro, mas também do seu desenvolvimento físico.

Esse desafio produziu um sistema eficiente de solução que organiza os elementos essenciais do problema e as diversas competências do cérebro em um plano que promove a sua resolução.

Um dos problemas que pareceu exigir prioridade, à medida que as concorrências por mercadorias $e$ serviços aumentaram, foi a garantia de custos menores. Suscetível a esta necessidade, à medida que o sistema de solução de problemas foi desenvolvido, ele foi dotado de uma ampla gama de técnicas, abordagens e métodos específicos para a obtenção daquilo que o consumidor desejava, a custos mais baixos.

Como Sistema para solução desses problemas, Miles desenvolve, em 1947, a Análise do Valor ou Engenharia de Valor, que tem sido aplicada no departamento de compras da General Eletric (GE) americana como sistema de solução de problemas com a área de conhecimento e as técnicas de suporte para a conquista de custos menores.

Segundo Miles (1972:3), a Análise do Valor é um sistema de solução de problemas implementado através do uso de um conjunto específico de técnicas, um corpo de conhecimento e um grupo de habilidades ensinadas. Ela é uma abordagem criativa e organizada, que tem como propósito a identificação eficiente de custos desnecessários, isto é, custos que não agregam qualidade, uso, durabilidade, aparência ou características solicitadas pelo consumidor.

A Análise do Valor, quando aplicada aos produtos, auxilia na utilização ordenada de abordagens melhores, materiais alternativos, processos mais modernos e habilidades de fornecedores especializados. Ela enfoca a atenção da engenharia, produção e compras em um objetivo - um desempenho equivalente por um custo menor.

Assim, o "Target Costing" - ou "genka kikaku" em japonês - ou Custeio Alvo foi originalmente criado pelos japoneses nos anos 60 baseado na idéia americana chamada Engenharia de Valor, transformada em um sistema dinâmico de redução de custo e planejamento de lucro. Esta técnica, Engenharia de Valor, era uma abordagem organizada da engenharia para determinar como produzir os produtos frente à escassez de materiais, tornando-se, mais tarde, um esforço organizado para examinar como fornecer as características ou funções necessárias em um produto a um menor custo possível.

O Target Costing pode ser definido como sendo um modelo de gerenciamento de lucros e custos, desenvolvido principalmente para novos produtos (ou que sofram alterações no seu projeto), visando trazê-los para uma situação de mercado, tendo um preço competitivo, proporcionando um retorno do 
investimento durante todo o seu ciclo de vida a um custo aceitável determinado pelo seu preço de venda. Possui vários objetivos: (a) otimização do custo total do produto, sem fazê-lo perder, contudo, seu padrão de qualidade; (b) alcançar o lucro-alvo esperado, tornando a obtenção do custo-alvo uma atividade de administração do lucro por toda empresa; e (c) planejar estrategicamente os lucros e custos, formulando planos estratégicos com a integração de todos os setores da empresa, dentre outros.

Para Ansari (1997, TC3),

Custeio-Alvo é um sistema de planejamento de lucro e gerenciamento de custos, definido pelo mercado, tendo como foco central o cliente, envolvendo no projeto várias áreas da empresa.

Para Sakurai (1997:49), Custo Meta ou Custeio Alvo é:

Um método abrangente de gerenciamento estratégico de custo que envolve a redução de custos durante todo o ciclo de sua ocorrência [...] com produtos projetados e reprojetados com mais freqüência, os esforços de redução de custos acabam se concentrando no processo de projeto.

Em resumo, segundo Rocha (1999:84), "Custeio Alvo é o processo pelo qual se alcança o Custo-Alvo."

Este sistema foi criado no Japão, na década de 60 , tendo se popularizado no ocidente anos mais tarde, na década de 80 , com a tradução de obras de autores japoneses, principalmente por alemães e norte-americanos. Possui três grandes características: 1) custo determinado pelo mercado; 2) integrar a empresa como um todo; 3) planejar os lucros e custos para o longo prazo (Cooper et al., 1999).

Sua fundamentação teórica é baseada em seis princípios: 1) custos guiados pelo preço, ou seja, o custo é dado pelo preço de mercado e não o contrário; 2) enfoque no consumidor; 3) enfoque no projeto, dizendo que os custos devem ser otimizados antes da sua entrada no processo produtivo; 4) envolvimento da empresa como um todo; 5 ) orientação para o custo do ciclo de vida; e 6) o envolvimento da cadeia de valor.
Neste sentido, o propósito do Target Costing é assegurar lucros adequados através da realização simultânea do planejamento de lucro e de custo. Butscher et al. (2000) fazem a seguinte afirmação: o conceito de Target Costing consiste de seis passos principais. Uma condição que absolutamente precisa ser atendida para o sucesso de uma abordagem voltada para o mercado é a determinação exata das dimensões alvo, tais como custo e projeto do produto. Segundo Butscher et al. (2000), os seis passos foram elaborados para atingir exatamente isto, mas é necessário muito trabalho detalhado e acurado, como segue:

1. Definição dos segmentos alvo: o primeiro passo é definir claramente os segmentos de mercado que serão o alvo de venda do produto.

2. A identificação das vantagens e desvantagens competitivas: o projeto de um novo produto deve ser baseado em uma análise das vantagens e desvantagens competitivas, tanto para o produto que ele irá substituir como para os produtos concorrentes no mercado.

3. O posicionamento do novo produto dentro dos segmentos alvo: esse posicionamento precisa ser visto no contexto da estratégia global da companhia.

4. Sintonizando o projeto e preço do produto: no item 2, as vantagens e desvantagens competitivas foram identificadas para estabelecer quais melhorias no projeto geral do produto são as mais necessárias. Para sintonizar o projeto e o preço do produto deve-se analisar as preferências dos consumidores, porque, quanto mais benefícios um consumidor obtém do uso de um produto, maior o valor percebido deste produto, e maiores são suas chances de ser selecionado entre os produtos concorrentes.

5. Simulações de mercado: O projeto ideal do produto foi estabelecido baseado na matriz de vantagens competitivas e nos valores das características específicas do produto.

6. Determinação do Target Cost: O custo máximo permissível é calculado pela simples subtração da margem alvo do preço ótimo. Este valor do custo total é distribuído entre os diferentes componentes e características do produto, de acordo com sua contribuição para o valor global (Butscher et al., 2000).

Estas características diferenciam o Target Costing dos sistemas tradicionais de custos. Esses sistemas 
tradicionais geralmente começam de dentro para fora, para o desenvolvimento de produto e atribuição de preço, que podem ser descritos pelas características abaixo:

(1) o desenvolvimento do novo produto é orientado pelo que os engenheiros desenvolveram, não pela demanda do mercado; (2) os preços são determinados em uma base custo-mais, o que significa que a margem alvo simplesmente é adicionada ao custo final do produto; (3) a voz (o desejo) dos consumidores é ouvida com atraso - se é que é ouvida - no processo de desenvolvimento do produto, ajudando apenas a sintonizar o produto quase pronto; (4) a cooperação entre os engenheiros e o pessoal de marketing é mínima, os engenheiros desenvolvem o produto e o pessoal de marketing tenta vendê-lo.

O resultado destas características é um conjunto de produtos com excesso de engenharia que não atende às exigências dos consumidores e com atribuição de preço completamente incorreta, desperdiçando enormes lucros e potenciais de venda.

\section{A PESQUISA}

A indústria norte-americana não percebeu o potencial da Engenharia de Valor como uma ferramenta sistemática de planejamento de lucro e de custo, e pouco fez após a Segunda Guerra. Neste período, os japoneses adotaram várias técnicas ocidentais, entre elas, a Engenharia de Valor, criando o Target Costing, um sistema mais ágil de gerenciamento de custos e planejamento de lucros, revolucionando a indústria japonesa nas décadas de 60 e 70 (Smith et al., 1999:4).

Aproveitando o potencial da Engenharia de Valor idealizado por Miles, a indústria japonesa expandiu os conceitos básicos desta ferramenta para o processo de Target Costing. Hoje mais de $80 \%$ de todas as indústrias de montagem no Japão, como a automotiva, a de eletrônicos, a de ferramentas, usam o Target Costing (Ansari, 1997).

O Sistema de Gerenciamento de Custo e Planejamento de Lucros, denominado "Target Costing", é perfeitamente aplicável em indústrias de produção em processo, ou seja, as que fabricam produtos essencialmente homogêneos e contínuos, principalmente quando a empresa atua no mercado do tipo concorrência monopolista, em que há vários vendedores (fabricantes) e vários compradores ou consumidores. Nesse modelo, os preços são determinados pelo mercado ou consumidores e, por sua vez, a formação de preços deve levar em conta o preço dos concorrentes, nível de qualidade, produto substituível, gosto e hábitos dos consumidores devido à existência de concorrentes no mercado organizado. Já esse mesmo sistema não se aplica, com a mesma eficiência, numa atividade de produção sob encomenda, na qual os custos e preços são projetados de acordo com a especificidade de cada produto. Nesse caso, a influência da concorrência não se restringe ao preço e à qualidade do produto e sim à sua característica e à especialidade do fabricante.

No Brasil, não se tem notícia se existe alguma empresa que utiliza o "Target Costing" como Sistema de Gerenciamento de Custos. Existem algumas literaturas que tratam do tema, elaboradas por autores japoneses, como Sakurai e Monden e alguns artigos publicados de autoria do prof. Welington Rocha.

Incomodado com este quadro, buscou-se, com este trabalho, fazer um estudo quanto ao Método de Custeio e Sistemas de Custos - principalmente o Target Costing, objeto do estudo - utilizados pelas empresas localizadas em municípios do estado de Santa Catarina. A pesquisa foi realizada em $48 \mathrm{em}-$ presas localizadas nos municípios de Itajaí, Navegantes, Ilhota, Gaspar, Blumenau, Brusque e Joinville. A classificação foi baseada em número de empregados superior a 500, conforme relação obtida junto ao Serviço de Informações Empresariais da Federação das Indústrias do Estado de Santa Catarina - FIESC/julho/2002. Do total de 48 empresas selecionadas, conseguiu-se entrevistar os gestores de 35 empresas, sendo sete do setor de alimentos; dez do setor têxtil; cinco do setor de vestuário; oito do setor metal-mecânico; quatro do setor de plásticos; e uma do setor de revestimento, representando $72,9 \%$ do montante das empresas selecionadas. Das sete empresas do setor de alimentos entrevistadas, duas estão sediadas nos municípios de Chapecó e Videira, mas foram consideradas, levando em conta o grau de representatividade destas empresas no estado.

Após a análise dos resultados obtidos no ambiente empresa, buscou-se, no ambiente acadêmico, 
investigar se o resultado obtido sobre os Métodos, Técnicas, Filosofias ou Sistemas de Custos utilizados pelas empresas entrevistadas têm alguma relação com a ementa e a ênfase que é dada ao Sistema de Gerenciamento de Custos "Target Costing" pelos professores que lecionam as disciplinas da área de custos nos cursos de Ciências Contábeis e Administração das principais Instituições de Ensino Superior localizadas nos municípios delimitados no projeto.

Foram encaminhados, via correio eletrônico, vinte e três (23) questionários para os professores selecionados e, destes, retornaram dezoito (18) que representam $78,3 \%$ (setenta e oito vírgula três por cento) do total distribuído, os quais foram tabulados na mesma ordem das questões definidas no questionário.

Finalmente, foi realizada a análise documental com base nas ementas fornecidas pelas coordenações dos cursos de Ciências Contábeis e Administração.

\section{ANÁLISE DE RESULTADOS}

\subsection{Dados do Ambiente - Empresa}

\subsubsection{Cargos e Titulação dos gestores entrevistados}

Inicialmente, procurou-se identificar os cargos e as titulações dos entrevistados; constatou-se que $49 \%$ dos entrevistados ocupam o cargo de Gerente ou Coordenador de Custos (destes, 58\% são contadores, $26 \%$ são administradores, e os outros $16 \%$ são cargos ocupados por economista, engenheiro e matemático); $34 \%$ são Controller, $11 \%$, Contadores e $6 \%$, outros cargos, conforme demonstrado no gráfico 1 , a seguir.

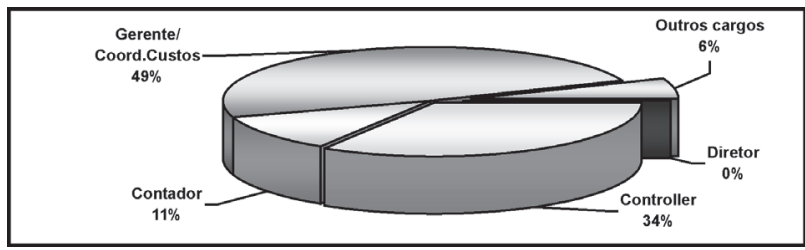

Gráfico 1 - Cargos dos Entrevistados

Quanto à titulação acadêmica dos entrevistados, constatou-se que: $63 \%$ são graduados em Ciências
Contábeis; 17\%, Administração; 14\%, Economia; e 6\%, outros cursos, como Matemática e Engenharia. Observou-se ainda que $66 \%$ dos gestores entrevistados possuem pós-graduação em nível de Especialização; 3\%, Mestrado; e 31\% não possuem nenhum curso de pósgraduação, conforme demonstrado nos gráficos 2 e 3.

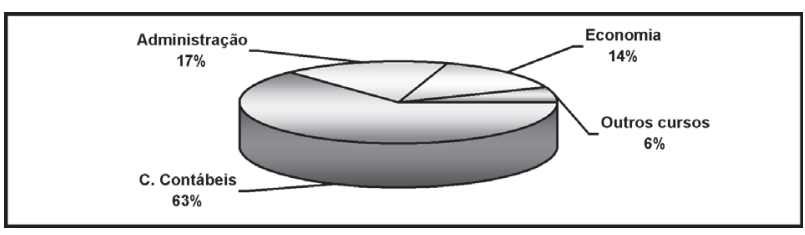

\section{Gráfico 2 - Titulação Acadêmica em Nível de Graduação}

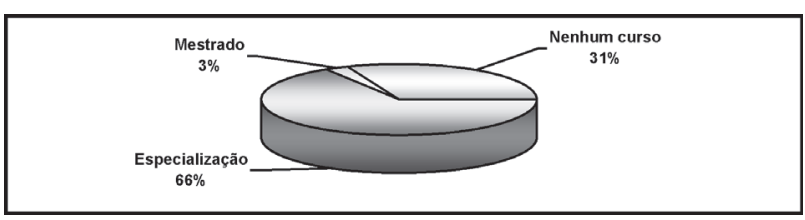

\section{Gráfico 3 - Titulação Acadêmica em Nível de Pós-Graduação}

Diante do quadro demonstrado anteriormente, percebeu-se que as áreas de custos são ocupadas, em grande maioria, por contadores com curso de pósgraduação em nível de especialização, portanto o resultado da pesquisa baseou-se na premissa de que os entrevistados são competentes e têm amplo conhecimento da matéria, objeto do estudo.

\subsubsection{Método de Custeio}

Questionados sobre o Método de Custeio utilizado pelas empresas, $63 \%$ dos entrevistados responderam que utilizam uma combinação do Absorção e o Direto/Variável; 31\% utilizam apenas o Absorção; e $6 \%$ utilizam apenas o Direto/Variável, conforme demonstrado no gráfico 4.

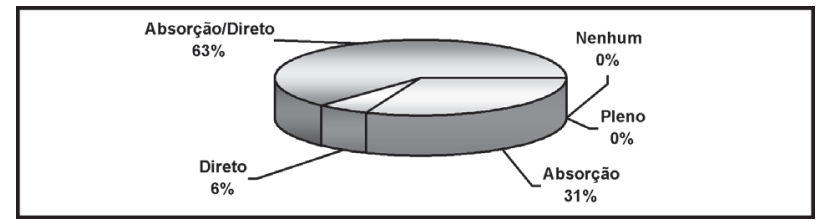

\section{Gráfico 4 - Nível de utilização dos Métodos de Custeios}

Para os gestores entrevistados, independentemente do ramo de atividade, a utilização do Custeio 
por Absorção para a avaliação do estoque visa principalmente atender à exigência societária e fiscal, porque este método de custeio, além de ser imposto pela legislação, também se adapta perfeitamente aos softwares existentes no mercado e não fere os Princípios Fundamentais da Contabilidade preconizados pela Resolução 750/93 do CFC.

Da mesma forma, $63 \%$ das empresas entrevistadas utilizam uma combinação do Custeio por Absorção com o Custeio Variável/Direto. O Custeio Direto/ Variável, segundo os gestores, é utilizado para fins decisórios, sendo a Margem de Contribuição sua principal informação. Esta ferramenta visa auxiliar o gestor na decisão de fabricar ou não determinado produto, aceitar ou não determinada encomenda. Neste caso, o custo de fabricação é composto apenas dos custos variáveis e os custos fixos deverão ser descarregados nos resultados; no entanto, como a empresa trabalha também com o Método de Custeio por Absorção, os estoques ou os custos dos produtos vendidos são avaliados por este método.

\subsubsection{Margem de Contribuição e Custo Padrão}

Quanto à Margem de Contribuição e Custo Padrão que são utilizados pelas empresas, $51 \%$ dos entrevistados responderam que utilizam uma combinação de Margem de Contribuição e o Custo Padrão; 26\% utilizam apenas o Custo Padrão; 17\% utilizam só a Margem de Contribuição; e 6\% não utilizam nenhum dos Métodos ou Sistema anteriormente citados.

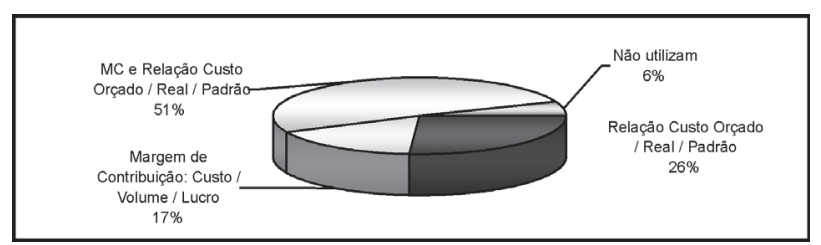

Gráfico 5 - Nível de utilização da Margem de Contribuição e Custo Padrão

Os gestores das empresas que utilizam uma combinação de Margem de Contribuição e o Custo Padrão afirmaram que utilizam a Margem de Contribuição tendo o Custeio Variável como base dessa informação, porque esta ferramenta de gestão de custos atende na decisão de: formação de preços; de fabricação ou não de determinado produto. A razão para a utilização do Custo Padrão é o fato deste sistema ter a propriedade de medir a eficiência de todo o processo produtivo seja ela de recursos materiais, financeiros ou humanos.

Quanto aos gestores que afirmaram que não utilizam nenhum dos Sistemas de Custos para tomada de Decisão e Controle acima citados, percebeu-se, durante a entrevista, que na realidade utilizam o Custo Padrão, porque, apesar da forma rudimentar de gerenciar estes custos, o gestor tem procurado comparar aquilo que foi gasto com o valor que foi planejado no ato do fechamento do negócio.

\subsubsection{Sistemas de Gerenciamento de Custos}

Quanto ao Sistema de Gerenciamento de Custos, Métodos ou Filosofias utilizados pelos gestores das empresas entrevistadas, constatouse que: $11 \%$ destas utilizam, mesmo que parcialmente, o Método denominado ABC (Activity Based Costing), para alocação dos custos indiretos em alguns produtos onde existe facilidade de identificação das atividades; $11 \%$ utilizam o UEP (Unidade de Esforço de Produção), onde são alocados aos produtos apenas os custos de transformação como Mão-de-Obra-Direta e Custos Indiretos de Fabricação; 6\% utilizam, parcialmente, o Sistema de Gerenciamento de Custos "Target Costing". Essas empresas utilizam apenas alguns princípios desta ferramenta de gestão de custos, tais como: (a) formação de preço de venda, quando o mercado já possui um preço referencial, e (b) fabricação de produto de acordo com a exigência do cliente consumidor; $3 \%$ utilizavam o Sistema de Gestão Econômica (Gecon), mas atualmente estão utilizando apenas algum fundamento em razão da estabilidade econômica que inviabilizou o uso do sistema, portanto as empresas estão migrando para outros sistemas; $29 \%$ utilizam, parcialmente, uma combinação de várias filosofias de gerenciamento como: ABM, TQM, TOC, JIT e o Kaizen, no processo de gerenciamento do seu custo de produção. Segundo os entrevistados, é utilizada uma combinação dessas filosofias de gestão para os seguintes objetivos: o JIT como processo de gerenciamento de estoque; o TQM 
como ferramenta de qualidade; o Kaizen como ciclo de controle de manufatura, melhoria constante e redução de custos; a TOC para a otimização da produção conforme o tipo de produto fabricado; O ABM como ferramenta para gerenciamento de processos; e os outros $51 \%$ afirmaram que não utilizam nenhum dos Métodos, Sistemas ou Filosofias apresentados no gráfico 6. Entretanto, percebe-se que, de forma indireta e parcial, são utilizados alguns fundamentos relacionados no roteiro de entrevista. Esta constatação baseia-se nas seguintes informações das empresas: 1) buscam a qualidade contínua dos seus produtos - TQM; 2) estabelecem os seus preços a valor de mercado - Target Costing; 3) perseguem melhoria contínua aos processos Kaizen; 4) mantêm controle permanente sobre os estoques - JIT.

O que surpreende é que, dentre estas empresas que afirmam não utilizar nenhum Sistema, Método ou Filosofia de Custos, estão aquelas que possuem mais de 5.000 empregados e utilizam apenas o Custeio por Absorção e o Direto/Variável, e Margem de Contribuição e Custo-Padrão, de forma eficiente para as necessidades da organização.

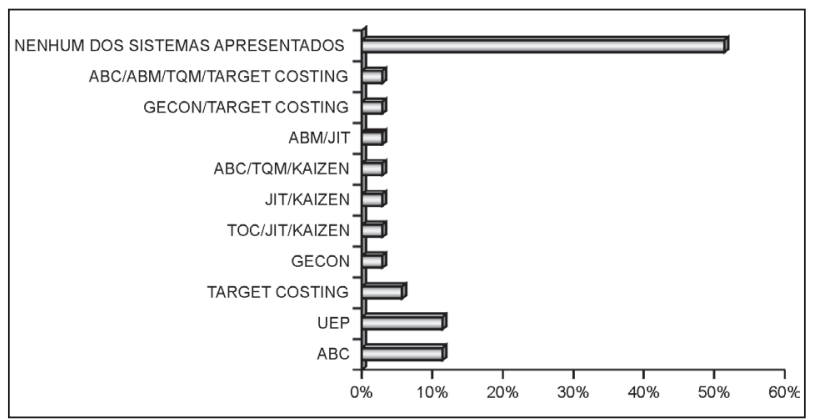

Gráfico 6 - Nível de utilização do Sistema, Método ou Filosofia de Custos

\subsubsection{Metodologia para determinar o preço de venda}

Quando questionada qual metodologia as empresas adotam para estabelecer o preço de venda de seus produtos, constatou-se que $46 \%$ utilizam o preço de mercado; $31 \%$ utilizam o custo de produção Mark-up; e 23\% utilizam uma combinação dos dois métodos, ou seja, durante o projeto utilizam o Mark-up, como base de referência, e depois comparam com o preço de mercado para efetuar a análise quanto à viabilidade, ou não, de se fabricar o produto, conforme demonstrado no gráfico 7 abaixo:

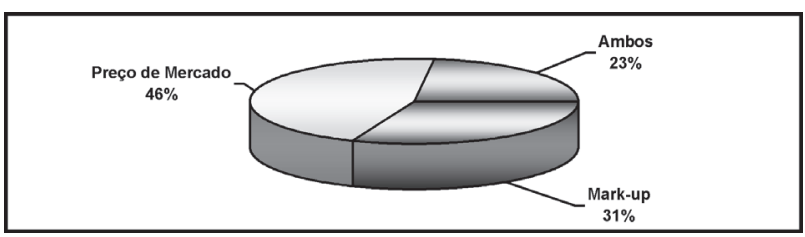

\section{Gráfico 7 - Método utilizado para estabelecer o preço de venda}

As decisões de preços são decisões que os administradores tomam sobre o que cobrar pelos produtos e serviços que oferecem. Essas decisões influenciam diretamente nas receitas das empresas, que devem superar os custos totais, se desejam obter lucros.

\subsubsection{Uso do Mark-up para formação de preço de venda}

Percebeu-se, na pesquisa, que ainda um percentual expressivo (31\%) das empresas entrevistadas utilizam o índice de formação de preço de venda baseado no Mark-up.

Considerando as afirmações dos entrevistados, conclui-se que o preço de venda e o custo do produto são baseados da seguinte forma: (1) a partir do custo de produção ou mark-up. Essa é a metodologia para formar o preço de venda, daí o comercial estar ciente sobre qual deve ser o preço e trabalhar com a flexibilidade, fazendo-se um acompanhamento com base na margem de contribuição; (2) a empresa sempre trabalha com o custo de produção mark-up, mas, de olho no mercado, coloca um ao lado do outro e verifica se o preço é competitivo ou não; (3) inicialmente, para estabelecer o preço de venda, utiliza-se o mark-up, na verdade depois é comparado com o preço de mercado, então se dispõe de um preço orientativo, e o setor comercial, dentro da política de vendas, é o que estabelece o preço de venda definitivo baseado no preço de mercado; (4) nos três casos, o custo do produto é estabelecido na fase do projeto, evidentemente que, na medida do possível, estes custos sofrem alguns ajustes, se necessário, durante a fase de produção.

Com base nas afirmações dos entrevistados, conclui-se que as empresas utilizam o Mark-up no 
primeiro momento, e depois ajustam ao preço de mercado para formar o seu preço de venda.

Neste sentido, para uma empresa poder determinar um Mark-up básico, de acordo com cada linha de produtos vendidos que poderá ser o Mark-up por produto, ou por linha, leva-se em consideração não somente o custo por absorção, mas também as despesas operacionais, financeiras e outros custos que poderão ser diferentes de cada produto ou linha. Portanto, um dos fatores que mais contribuíram para que as empresas entrevistadas, no primeiro momento, utilizassem o índice Mark-up, foi a diversificação de produtos em termos de tipos, tamanhos, cores, modelos etc.

\subsubsection{Preço de Mercado para formação do Preço de Venda}

Os gestores das empresas entrevistadas (46\%) que utilizam o mercado para estabelecer o preço de venda informaram que este preço é formado por um conjunto de variáveis: o mercado, os concorrentes, os clientes, os consumidores e a demanda e oferta de produtos.

Neste caso, a empresa está utilizando um dos princípios do Target Costing, já que leva em conta o mercado, concorrentes, clientes e consumidores para definir o preço de venda de seus produtos, além da marca e dos investimentos em pesquisa, desenvolvimento e marketing que fornecem a base de competitividade de uma empresa; e o custo do produto é estabelecido antes de iniciar a produção.

Neste sentido, a busca constante pela sobrevivência empresarial é o principal objetivo quando as empresas estão assoladas pelo excesso de capacidade, pela concorrência intensa ou por mudanças nos desejos dos consumidores. Neste caso, os lucros tornam-se menos importantes que a sobrevivência, desde que os preços cubram os custos variáveis e alguns custos fixos para que a empresa continue a funcionar. Entretanto, a sobrevivência é o objetivo de curto prazo; no longo prazo, a empresa terá que aprender a agregar valor aos seus produtos para se manter no mercado.

\subsubsection{Metodologia para estabelecer os custos}

Constatou-se que $88,6 \%$ das empresas entrevistadas responderam que estabelecem os seus custos na fase de projeto, e outras $11 \%$ afirmaram que os custos dos produtos são definidos após a sua elaboração, ou seja, quando o produto vai para o estoque ou ao cliente. Verificou-se que os $11 \%$, que representam 4 empresas entrevistadas, também trabalham sob encomenda, mas a maior parte da produção vai para estoque; posteriormente, os produtos são vendidos, através de representantes distribuídos nas mais diversas regiões do país.

Os outros $89 \%$, que representam 31 empresas entrevistadas, são empresas que trabalham exclusivamente sob encomenda. O preço é combinado no ato da negociação e o custo é definido nesta mesma oportunidade com base no custo-padrão interno da empresa. A diretoria poderá ajustar o preço de venda e os custos dentro da margem de lucro admissível da organização. Esta afirmação condiz com o conceito de Rocha (1999, p.84), "Custo Alvo é o custo máximo admissível de um produto ou serviço para que, dado o preço de venda que o mercado aceita, consiga o mínimo de rentabilidade que se quer."

\subsubsection{Outras Análises de Conteúdo}

Quais os Motivos e os Benefícios que Levaram a Empresa a adotar o Método de Custeio?

Conforme apresentado no gráfico 4, 31\% afirmaram que utilizam o Custeio por Absorção; $63 \%$ utilizam o Custeio por Absorção e Custeio Direto/ Variável; e apenas 6\% utilizam o Custeio Variável/Direto para avaliar os custos dos produtos fabricados.

Durante a entrevista, constatou-se que os principais motivos que levaram as empresas a utilizar o Custeio por Absorção foram: 1) atender à exigência fiscal e contábil; 2) por ser aceito pela auditoria externa; 3) melhor se adaptar ao sistema de processamento utilizado, mesmo considerando uma certa dose de arbitrariedade na alocação dos custos indiretos aos produtos.

As empresas que utilizam o Custeio Direto/Variável procedem, assim, ao objetivo de auxiliar na tomada de decisão, fornecendo uma melhor informação por não contemplar os custos fixos, eliminando o arbitramento na distribuição dos custos e despesas fixas, possibilitando verificar a participação e capacidade de cada produto na diluição dos custos e despesas fixas. 
Quais os Motivos que Levaram a Empresa a Adotar a Margem de Contribuição e o Custo Padrão?

Observou-se que $51 \%$ dos entrevistados, conforme apresentado no gráfico 5 , responderam que os motivos que levaram a empresa a adotar a Margem de Contribuição e o Custo Padrão foram: 1) simplicidade na implementação; 2) adaptação ao Sistema; 3) facilidade para estabelecer a Margem de Segurança na decisão de produzir; 4) servir para fins gerenciais e para medir e controlar a eficiência; 5) é um Sistema que atende às necessidades gerenciais da empresa.

As empresas que utilizam Custo-Padrão afirmaram que um dos motivos para a sua implementação é a existência de sistemas de processamento (software) existentes no mercado passíveis de adaptações e programados para direcionar o uso do Custo-Padrão. Este sistema mostra, via on-line, as informações necessárias e, no final do mês, possibilita o comparativo entre o padrão e o real, para a análise e para tomar as decisões corretivas necessárias em tempo hábil.

Quais os Motivos que Levaram a Empresa a Adotar o Sistema, Método ou Filosofias de Custos?

Procedendo à análise de conteúdo do resultado das entrevistas com os gestores, constataram-se os seguintes motivos que levaram as empresas a adotarem o Método de Custo: ABC, UEP, Sistemas de Gerenciamento de Custos Target Costing, Sistema de Gestão Econômica - Gecon, e filosofia de gerenciamento de custos como TQM, ABM, JIT e Kaizen: (1) forma de alocar os custos indiretos aos produtos específicos; (2) velocidade na apuração do resultado e simplicidade na comparação de valores existentes; (3) atende às necessidades atuais da empresa; (4) por entender que o acompanhamento dos custos é o diferencial competitivo importante e necessário para o sucesso do negócio.

Apesar da afirmação dos entrevistados de que utilizam alguns dos principais fundamentos dos Sistemas, Métodos ou Filosofias de Custos citados no roteiro de entrevista, percebeu-se que estes mesmos gestores desconhecem a operacionalização destes dentro do processo produtivo da empresa, porque, em todos os casos, foram utilizados parcialmente os conceitos e princípios definidos em cada sistema, métodos ou filosofias para produtos e setores específicos, mas não souberam desenvolver nenhum comentário sobre a sua operacionalização, exceto aquelas citadas nas literaturas acadêmicas.

O Senhor Conhece o Sistema de Gerenciamento de Custos Denominado Target Costing ou Custeio Alvo?

Diante deste questionamento, constatou-se que $69 \%$ dos entrevistados desconhecem o Sistema de Gerenciamento de Custos denominado Target Costing ou Custeio Alvo e apenas 31\% responderam que conhecem o Sistema.

Os gestores entrevistados que afirmaram que conhecem o Sistema de Gerenciamento de Custos denominado Target Costing tiveram esse conhecimento através de literaturas e treinamentos realizados na USP e FGV-Rio, nos cursos MBA, mestrado em Engenharia da Produção, promovido pela UFSC e no curso em nível de especialização, sendo $70 \%$ na área de Contabilidade, especificamente na área de Custos, Auditoria e Controladoria, outros $30 \%$ em administração e finanças.

\section{Por que o Target Costing não é Aplicado na Empresa?}

Realizando a análise de conteúdo dos gestores das empresas entrevistadas, quanto aos motivos da não implementação do Sistema de Gerenciamento de Custos denominado "Target Costing", chegou-se aos mais comuns: (1) desconhecimento da operacionalização do processo; (2) uma mudança muito radical de um Sistema demandaria custos altos e seria preciso verificar os benefícios que esse sistema proporcionaria em termos de resultados antes de adotá-lo; (3) grande diversidade de produtos com características distintas; (4) o Sistema, métodos ou filosofias utilizados pela empresa atendem perfeitamente as suas necessidades; os gestores afirmaram que estão satisfeitos com a eficácia do sistema ou método de gestão de custos utilizado no momento; (5) demandaria uma mudança estrutural da organização e uma mudança comportamental dos colaboradores em geral; (6) acredita-se que não se aplica em qualquer atividade.

Diante dos motivos acima elencados pelos entrevistados, percebeu-se que os gestores não 
esboçaram nenhum interesse em rever ou implementar o Target Costing, ou alguns outros Sistemas, métodos ou filosofias de Custos, em busca de novas alternativas para a Gestão Estratégica de Custos, com vistas à melhoria do desempenho empresarial para ser mais competitivo diante das incertezas e ameaças que estão presentes neste ambiente altamente concorrido. Ressalta-se este fato com os questionamentos de Miles (1972): $\left(1^{\circ}\right)$ Por que existe uma tendência natural da busca de alternativa apenas quando somos forçados pelas circunstâncias? $\left(2^{\circ}\right)$ Por que não antecipar esta busca? Considerando que os gestores estão satisfeitos com o desempenho dos métodos, filosofias e/ou sistemas atualmente utilizados, o primeiro questionamento de Miles reflete com precisão a atitude dos gestores.

\subsection{Ambiente Acadêmico}

No ambiente acadêmico, constatou-se que: dos professores respondentes, 50,0\% possuem a titulação acadêmica em nível de Especialização; 44,0\%, Mestrado e 6,0\%, Doutorado; 22,0\% participaram de Congresso Brasileiro de Contabilidade de Custos; e 6\% cursaram o MBA.

\subsubsection{Grau de conhecimento dos Métodos de Custeio, Filosofias ou Sistemas de Custos}

Investigou-se também o grau de conhecimento dos Métodos de Custeio, Sistema, Filosofias de Custos e Sistema de Gestão Econômica. Foram obtidos os seguintes resultados: dos 18 respondentes, $61 \%$ conhecem o Custeio Pleno e 100\% conhecem o Custeio por Absorção e o Direto/Variável. Em seguida, pesquisou-se quanto à ênfase dada ao Método Pleno, Absorção e Direto/Variável: constatou-se que: $17 \%, 89 \%$ e $83 \%$, respectivamente, abordam o assunto com profundidade, concluindo assim que o Método de Custeio Pleno não está presente nos planos de aula das disciplinas da área de custos.

Outra questão pesquisada foi o grau de conhecimento de Margem de Contribuição e Custo Padrão. Constatou-se que $95 \%$ e $90 \%$, respectivamente, conhecem esses sistemas, conforme gráfico 8, a seguir:

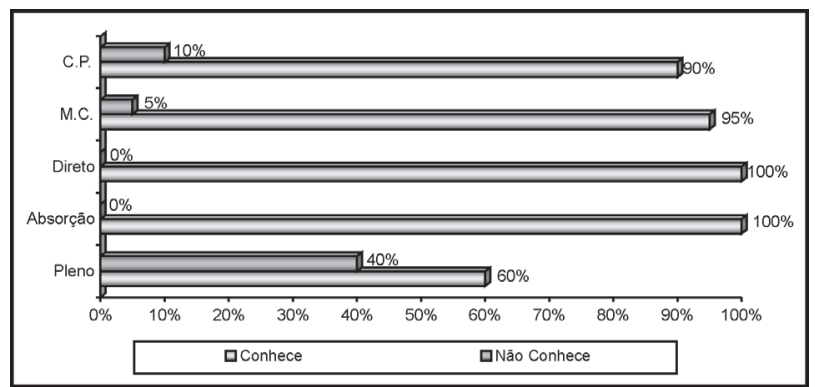

\section{Gráfico 8 - Nível de conhecimento do Método de Custeio, Margem de Contribuição e Custo Padrão}

Quanto à ênfase dada à "Margem de Contribuição e Custo Padrão": constatou-se que $83 \%$ e $50,0 \%$, respectivamente, abordam os temas com profundidade.

Na questão seguinte, foi perguntado se o professor conhecia os Métodos de Custos: ABC (Activity Based Costing); UEP (Unidade de Esforço de Produção); Filosofia de Gerenciamento como ABM (Activity Based Management); TOC (Theory of Constraints); TQM (Total Quality Management); JIT (Just-In-Time); Kaizen; sistemas como Sistema de Gestão Econômica -Gecon e Sistema de Gerenciamento de Custos "Target Costing", e obtiveram-se os seguintes resultados: $A B C$ é conhecido por $100,0 \%$ dos professores; O JIT, por $79 \%$; TOC e UEP, 61\%; ABM, TQM e Gecon, 55\%.a 58\%. Quanto ao Kaizen e o Target Costing, o nível de desconhecimento representa $61 \%$, ou seja, uma grande maioria de docentes desconhece os dois Sistemas, conforme apresentado no gráfico 9.

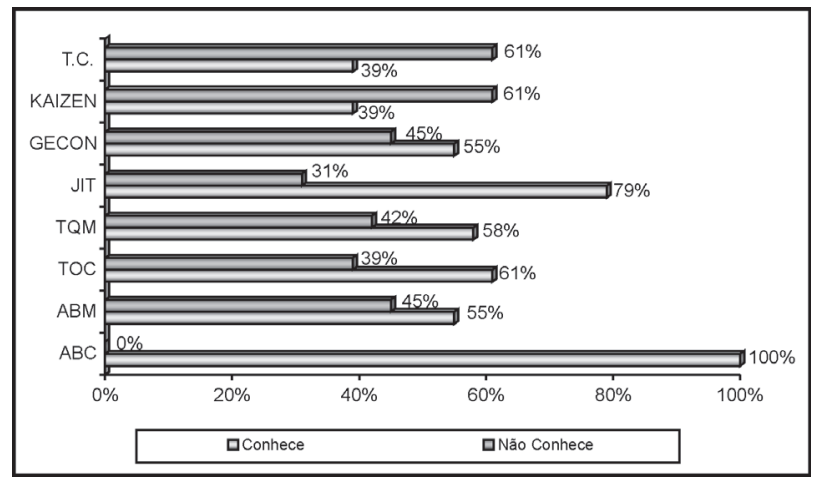

Gráfico 9 - Nível de conhecimento dos Sistemas, Métodos e Filosofias de Custos

Em seguida, foi pesquisada a ênfase que é dada aos Sistemas, Métodos e Filosofias de Custos, citados acima, na sala de aula e constatou-se que: 
apenas o ABC é abordado, mas superficialmente, representando $78 \%$ dos entrevistados, e a TOC com $50 \%$, mas a maioria não comenta o tema em sala de aula. No caso específico do Target Costing, 39\% afirmaram que conhecem e outros $61 \%$ que desconhecem o sistema. Dentre estes, $83 \%$ dos professores respondentes simplesmente não fazem nenhuma referência ao tema. Este quadro pode ser justificado no item 10 do questionário, onde se constatou que: os que não conhecem ou que conhecem apenas em literaturas representam $63 \%$.

Estes dados vêm ao encontro das razões que levaram o Sistema de Gerenciamento de Custos "Target Costing" a tornar-se pouco conhecido, tanto nos meios empresariais como nos meios acadêmicos. Se for feito um paralelo entre os Métodos de Custeios por Absorção e Variável e a Margem de Contribuição e o Custo Padrão, percebese que ambos são ministrados com certa profundidade nos cursos de Ciências Contábeis e Administração das Instituições de Ensino Superior, e em contrapartida as empresas os têm utilizado para gerenciar os seus custos. Diferentemente tem ocorrido com os Sistemas de Custos, com a exceção do Método ABC (Activity Based Costing), tendo-se constatado que a totalidade dos professores entrevistados conhece o Método e dá certa ênfase em sala de aula, mesmo que superficialmente, isso pode ter sido suficiente para que algumas empresas implantassem o método $A B C$ para gerenciar seus custos.

\subsubsection{Ementas das disciplinas de Custos ministradas nos cursos de Ciências Contábeis e Administração das Instituições de Ensino Superior}

Como complementação dos dados acima, foi analisado o ementário das disciplinas de Contabilidade de Custos I e II, Contabilidade Gerencial, Análise de Custos, Gestão Estratégica de Custos e Controladoria ministradas nos cursos de Ciências Contábeis e Administração nas Instituições de Ensino Superior em municípios delimitados na pesquisa, constatando-se que os conteúdos programáticos analisados não fazem nenhuma referência ao Sistema de Gerenciamento de Custos "Target Costing".
Diante das constatações apresentadas neste tópico e em 4.2.1, justifica-se o desconhecimento do Sistema de Gerenciamento de Custos "Target Costing" e outros sistemas ou filosofias de custos, nos meios empresariais, porque no meio acadêmico também este desconhecimento foi constatado, tanto nos docentes, quanto na elaboração das ementas das disciplinas. Entretanto, entende-se que as Instituições de Ensino Superior deveriam ser a vanguarda na divulgação de sistemas alternativos de gerenciamento de custos num ambiente altamente competitivo e globalizado.

\section{CONSIDERAÇÕES FINAIS}

O objetivo geral deste trabalho foi conhecer os Sistemas de Gerenciamento de Custos utilizados pelas empresas industriais de porte médio e grande, em municípios do estado de Santa Catarina, visando constatar as propensões à utilização do Target Costing. Pode-se considerar que este objetivo foi alcançado uma vez que se conseguiu diagnosticar que a maioria das empresas entrevistadas, por meio dos seus gestores da área de custos, não utiliza quaisquer Sistemas de Gerenciamento de Custos citados nesta pesquisa, em sua plenitude.

No que se refere ao levantamento dos sistemas de custos praticados pelas empresas e as condições favoráveis e desfavoráveis à implantação do Target Costing, com relação às empresas entrevistadas, verificou-se que a utilização de Sistemas Integrados de Informações como, SAP (Sistema de Administração da Produção) e o ERP (Sistemas Empresariais Integrados) para o gerenciamento integrado de produção, favorece a implantação do Target Costing nessas empresas. Também se conseguiu diagnosticar que, no momento, não existe ambiente favorável para a sua implantação nas empresas pelas seguintes razões: (a) desconhecimento do Sistema e sua operacionalização pela maioria dos entrevistados; (b) as vantagens e desvantagens do sistema ainda não estão claras para a realidade das empresas entrevistadas; e (c) o sistema exige uma mudança de comportamento dos colaboradores na cadeia produtiva, sendo considerada uma tarefa difícil para a realidade cultural destas empresas.

Quanto ao papel das Instituições de Ensino Superior na transmissão de conhecimento e utilização 
do Sistema de Gerenciamento de Custos, delimitado na pesquisa, esse objetivo também foi atendido. Constatou-se que não existe formalmente transmissão de conhecimento conforme se verificou no ementário das disciplinas da área de custos dos cursos de graduação de Ciências Contábeis e Administração de Empresas das Instituições de Ensino Superior pesquisadas. Nas entrevistas com os docentes, essa constatação também se confirmou, já que sessenta e um por cento dos docentes pesquisados afirmaram desconhecer o Sistema de Gerenciamento de Custos denominado "Target Costing".

Diante desse quadro, acredita-se que a inclusão desse tema no conteúdo programático das disciplinas, Gestão Estratégica de Custos ou Contabilidade Gerencial e Controladoria ajudará a resolver parte desse problema, levando os docentes dessas disciplinas a pesquisar com profundidade o assunto para que possam transmitir aos alunos, principalmente aos da graduação.

Durante a pesquisa bibliográfica, percebeu-se que os autores têm buscado, incansavelmente, uma nova forma de gerenciamento de custos. No entanto, tais descobertas têm sido pouco aplicadas nas empresas pesquisadas, ou a sua operacionalização não tem conseguido despertar o interesse necessário para a sua implementação nessas empresas, que são as maiores interessadas na redução de seus custos, buscando constantemente a sua sobrevivência.

Constatou-se, portanto, durante todo o desenvolvimento do trabalho, um distanciamento entre o que a academia vem pesquisando ou divulgando e o que as empresas entrevistadas vêm utilizando na prática.

Talvez pelo fato de não se ter percebido a divulgação formal do Sistema, por parte dos docentes, que supostamente são os impulsionadores na disseminação do Target Costing, os gestores da área de custos, diretores e proprietários das empresas entrevistadas desconhecem a potencialidade do sistema para gerenciamento de custo e de lucro. Por conseguinte, não demonstraram nenhum entusiasmo quanto à possibilidade futura de implementar o Target Costing.

Em síntese, as principais conclusões com base nas empresas e Instituições de Ensino Superior pesquisadas foram as seguintes:

a) a maioria dos entrevistados das empresas selecionadas utiliza os métodos de custeio tradicionais como Absorção e Variável;

b) a maioria dos entrevistados desconhece o Sistema de Gerenciamento de Custo "Target Costing";

c) nas Instituições de Ensino Superior pesquisadas, não é dada ênfase ao Sistema de Gerenciamento de Custo "Target Costing", pelo menos nos cursos de graduação, por intermédio do seu corpo docente.

Diante destas constatações, acredita-se que deverá levar algum tempo para que sejam possíveis a aceitação e implementação deste sistema pelas empresas. Para que isto seja viável, deve-se começar a divulgar, não apenas o Target Costing, mas também outros sistemas citados no presente trabalho, junto aos alunos de graduação e de pós-graduação. Outra alternativa será a promoção de palestras e seminários nos meios empresariais, podendo tornar o sistema mais conhecido como ocorre no Japão, Estados Unidos e na Europa.

Espera-se que o resultado apresentado venha a contribuir para a divulgação dos Sistemas de Gerenciamento de Custos, especialmente o "Target Costing", nos meios empresariais e, principalmente, junto aos docentes e, destes, aos acadêmicos dos cursos de Ciências Contábeis e Administração. Além disso, que as informações contidas venham a incentivar futuros trabalhos sobre o tema, bem como implementar o Target Costing nas empresas, com o objetivo de demonstrar a potencialidade deste sistema para o planejamento de custos e de lucro. 


\section{REFERÊNCIAS BIBLIOGRÁFICAS}

ANSARI, Shahid et al. Management Accounting: Target Costing. São Paulo: McGraw-Hill, 1997.

BUTSCHER, Stephan A. et al. Market-Driven - Product Development - Using Target Costing to Optimize Products and Prices. Marketing Management Journal. USA. Summer. p.48-53. 2000.

COOPER, Robin et al. Develop Profitable New Products With Target Costing. Sloan Management Review Journal. USA. VI.40, ISS 4, p. 23-33, summer 1999.

MILES, Lawrence D. Techniques of Value Analysis and Engineering. 2.ed. USA. McGraw-Hill. 1972.
MONDEN, Yasuhiro. Sistemas de Redução de Custos: Custo-Alvo e Custo Kaizen. Porto Alegre: Bookmann, 1999.

ROCHA, Welington et al. Custeio-alvo: Target Costing. Revista Brasileira de Custos. São Leopoldo/RS. Vol. I, n1, p. 83-94,1ํ sem. de 1999.

SAKURAI, Michiharu. Gerenciamento Integrado de Custos. São Paulo: Atlas, 1997.

SMITH, Kim Langfield et al. Target Costing for Effective Cost Management: Product Cost Planning at Toyota Australia. Financial and Management Accounting Committee - IFAC. Study 10, Jun 1999.

NOTA:

Endereço dos autores:

KOKI ONO

Rua Uruguay, 508 - Itajaí

Santa Catarina - SC

88302-202

ANTONIO ROBLES JUNIOR

Av. Prof. Luciano Gualberto, 908 - prédio 3

Cidade Universitária - São Paulo - SP

05508-900 